\title{
Editorial
}

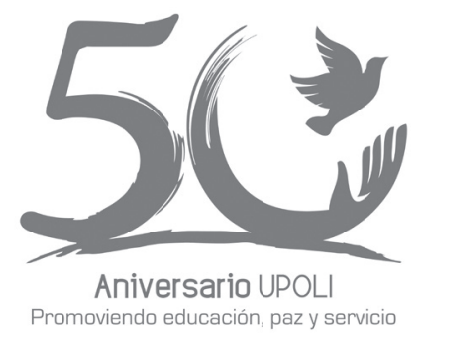

\section{Aniversario de fundación de la UPOLI}

\section{Medio siglo de testimonio cristiano, y de servicio educativo con calidad, talento y compromiso (1967-2017)}

La Universidad Politécnica de Nicaragua (UPOLI), es la primera universidad cristiana evangélica no confesional que se fundó en el país, y la segunda a nivel centroamericano. Es la tercera universidad establecida en Nicaragua, y una de las de mayor trayectoria, que ha alcanzado la privilegiada edad de 50 años de funcionamiento exitoso.

En el año 1967, la Convención Bautista de Nicaragua (CBN), aprobó el aspecto fundacional, y la lista de los 15 miembros del Patronato Fundador de la UPOLI. 2017 es el año del Centenario de la Obra Bautista en Nicaragua.

El 25 de noviembre del año 1967, se emitió el Decreto Ejecutivo No. 76-J, mediante el cual se autorizó el funcionamiento de la UPOLI, fecha que se celebra como su aniversario de fundación.

La trayectoria de servicio educativo de calidad, y apropiado a las necesidades del país, es algo que desarrollaron con éxito y heredaron los iniciadores de la Obra Bautista a los líderes fundadores de la UPOLI. La Historia de los 40 años de la UPOLI ${ }^{2}$ refiere que, al inicio de funcionamiento de la universidad, "...se sintió la necesidad de formar cuadros técnicos que reforzaran el aparataje de las necesidades sociales emergentes".
Las primeras carreras que abre la UPOLI fueron las de Asistentes Ejecutivos, Dibujo Publicitario, Electrónica, Educación Física,

Decoración de Interiores, Diseño y Enfermería

Esta opción y diseño de carreras apropiadas a la realidad y necesidad del país, en los inicios de vida de la universidad, es una prueba entre muchas más, del talento y la capacidad del liderazgo que fundó la UPOLI, que supo calibrar el momento y proponer una alternativa viable, provechosa para la vida del país.

La UPOLI, es una institución privada, de educación superior, y por convicción propia y designación estatal ha funcionado a lo largo de sus 50 años de vida, como una universidad de servicio público, sin ánimo de lucro.

La probada vocación de servicio público de la UPOLI se ha cumplido poniendo en evidencia la capacidad y talento en el desempeño,... pero además, ha sido visible y manifiesta una característica relevante que ha estado presente siempre, y es su compromiso, empeño de atención y servicio a los sectores más necesitados del país.

En sus 50 años de funcionamiento, la UPOLI se ha caracterizado, con pruebas claras y manifiestas

1 Rector de UPOLI (1980-2003), Rector Emérito, Miembro del Patronato Universitario UPOLI.

2 Historia de los 40 Años de la UPOLI (Sembrando con lágrimas...Cosechando con regocijo). 
de su efectivo aporte a la construcción del proyecto de Nación de Nicaragua, tanto en materia de investigación, formación profesional y de extensión amplia y diversa, con un efectivo cumplimiento de su lema: "Sirviendo a la Comunidad".

Durante este medio siglo la UPOLI también se ha distinguido por brindar aportes pioneros de notable beneficio para el país, pudiéndose mencionar: 1) El inicio de sus carreras en el área tecnológica; 2) el diseño en cierto momento de sus carreras en 2 etapas, a nivel de Técnico Superior; complementada con Licenciatura, generando posibilidades de inserción laboral entre etapas; 3) la fundación de la Clínica Academia de Medicina Alternativa ; 4) del Conservatorio de Música; 5) su prestigiada Escuela de Enfermería, la más antigüedad en el pacífico del país; 6) la apertura de 3 Recintos Regionales Universitarios; 7) ser la iniciadora de Nuevas Modalidades de Enseñanza (sabatina, dominical y por encuentros).

La UPOLI en todo este tiempo ha cumplido una efectiva y trascendente actividad académica-docente en sus 4 Recintos Universitarios (Managua, Rivas, Estelí y Boaco), así también en su extensión universitaria, atendiendo aspectos sensibles y esenciales de la vida de la Nación. A la par de su reconocida trayectoria académica que incluye el desarrollo de 15 carreras de grado (servidas en 8 Escuelas o Facultades), en las áreas de administración, finanzas, economía, artes musicales, deportes, teología, salud, jurídica y tecnológica, además de un significativo número de postgrados y maestrías, y también su empeño ha estado en atender con el mayor rigor posible la investigación científica.

... Desde finales de la década de los 90’s, ha logrado avanzar en su mejoramiento organizativo y funcionamiento integral, experimentando un crecimiento y desarrollo acelerado, una forma de reingeniería institucional de cara a la mundialización, a la extraordinaria producción de conocimientos, el auge de las tecnologías, y los nuevos paradigmas de la Educación Superior, tales como la cultura de paz, la educación en valores y derechos humanos, el desarrollo endógeno y sustentable. Desde esa época se ha dado la formulación de políticas claras y líneas estratégicas de desarrollo; el fortalecimiento de la labor informativa, y el desarrollo de la investigación.

También se llevaron a cabo numerosos proyectos orientados a la modernización y a fortalecer la labor de extensión de la Universidad, incluyendo la creación de los primeros institutos de investigación y organismos de proyección social (11 en total), entre ellos el Instituto de Investigaciones y Acción Social por la Paz "Martín Luther King" (IMLK).

El Instituto "Martín Luther King", como lo expresa el Dr. Miguel De Castilla, Asesor Presidencial para asuntos Educativos y Representante de la UNESCO en Nicaragua:

... es el único organismo de carácter académico en Nicaragua, y probablemente en la región, cuya misión institucional de investigación, docencia y extensión sea la paz", ya que al crear este Instituto en 1993 fue para "levantar, divulgar (...) y proponer la creación del paradigma de la Cultura de Paz (...) que contribuyera a superar una cultura de violencia...

Aunque pudiera parecer contradictorio, la UPOLI a sus 50 años es una institución joven, pero a la vez adulta, o con juventud acumulada, a como algunos expresan.

Recordamos que cada 50 años se daba la celebración judía del Jubileo, según la legislación sacerdotal ( $\operatorname{Lv} 25: 8$ ); el año empezaba con ayuno y arrepentimiento. Era un año santo y de liberación, donde se instaba que nadie abusara de otros, que se mostrara reverencia a Dios.

Que esta magna celebración de los 50 años de la UPOLI propicie un fortalecimiento de la fraternidad, la sensibilidad humana y cristiana que ha caracterizado a la familia upoliana.

2017 es entonces el año del 50 Aniversario de Fundación de la UPOLI, un momento cumbre de triunfo y de gloria, que evoca una jornada de fe, de perseverancia, de lucha inclaudicable de dela UPOLI. fundadores y continuadores de la Obra, de acción de gracias y reconocimiento de la presencia de Dios en todo momento, por haber permitido una trayectoria luminosa y trascendente, de aportes tangibles y de gran provecho para el pueblo nicaragüense.

Managua, 30 de marzo del 2017 